American Journal of Applied Sciences 7 (8): 1100-1108, 2010

ISSN 1546-9239

(C) 2010 Science Publications

\title{
Modeling and Controller Design of an Electro-Hydraulic Actuator System
}

\author{
${ }^{1}$ M.F. Rahmat, ${ }^{2}$ S. Md Rozali, ${ }^{1}$ N. Abdul Wahab, ${ }^{1}$ Zulfatman and ${ }^{3}$ Kamaruzaman Jusoff \\ ${ }^{1}$ Department of Control and Instrumentation Engineering, Faculty of Electrical Engineering, \\ University Technology Malaysia, UTM Skudai 81310, Johor, Malaysia \\ ${ }^{2}$ Department of Control, Instrumentation and Automation, Faculty of Electrical Engineering, \\ University Technical Malaysia Melaka, 76109 Durian Tunggal, Melaka, Malaysia \\ ${ }^{3}$ Faculty of Forestry, University Putra Malaysia, 43400 Serdang, Selangor, Malaysia
}

\begin{abstract}
Problem statement: Electro-hydraulic actuators are widely used in motion control application. Its valve needs to be controlled to determine direction of the motion. Mathematical modeling is a description of a system in terms of equations. It can be divided into two parts; physical modeling and system identification. The objective of this study was to obtain mathematical model of an electro-hydraulic system using system identification technique by estimating model using System Identification Toolbox in MATLAB. Approach: Experimental works were done to collect input and output data for model estimation and ARX model was chosen as model structure of the system. The best model was accepted based on the best fit criterion and residuals analysis of autocorrelation and cross correlation of the system input and output. PID controller was designed for the model through simulation in SIMULINK. The controller is tuning by Ziegler-Nichols method. The simulation work was verified by applying the controller to the real system to achieve the best performance of the system. Results: The result showed that the output of the system with controller in simulation mode and experimental works were improved and almost similar. Conclusion/Recommendations: The designed PID controller can be applied to the electro-hydraulic system either in simulation or real-time mode. The self-tuning or automatic tuning controller could be developed in future work to increase the reliability of the PID controller.
\end{abstract}

Key words: Electro-hydraulic actuator, system identification, ARX model, PID controller

\section{INTRODUCTION}

Electro-hydraulic actuator system: Electro-Hydraulic Actuators (EHA) are highly non-linear system with uncertain dynamics in which the mathematical representation of the system cannot sufficiently represent the practical system (Wang et al., 2009). The actuator plays a vital role in manoeuvring industrial processes and manufacturing line. The electro-hydraulic actuator can use either proportional valve or servo valve. It converts electrical signal to hydraulic power (Zulfatman and Rahmat, 2009). There are electro-hydraulic valve actuators which move rotary motion valves such as ball, plug and butterfly valves through a quarter-turn or more from open to close. There are also valve actuators which move linear valves such as gate, globe, diaphragm and pinch valves by sliding a stem that controls the closure element. Usually, valve actuators are added to throttling valves which can be moved to any position as part of a control loop.
Important specifications for electro-hydraulic valve actuators include actuation time, hydraulic fluid supply pressure range and acting type. Other features for these actuators include over torque protection, local position indication and integral pushbuttons and controls. The applications of electro-hydraulic actuators are important in the field of robotics, suspension systems and industrial process. This is because it can provide precise movement, high power capability, fast response characteristics and good positioning capability.

\section{MATERIALS AND METHODS}

In order to acquire the highest performance of the electro-hydraulic actuator, a suitable controller has to be designed. As the controller design require mathematical model of the system under control, a method of identifying the actuator need to be chosen so that the best accuracy of the model can be obtained. A model identification of electro-hydraulic position servo

Corresponding Author: Kamaruzaman Jusoff, Faculty of Forestry, University Putra Malaysia, 43400 Serdang, Selangor, Malaysia 
system based on hardware-in-the-loop simulation environment of Real-Time Workshop (RTW) and system identification toolbox in MATLAB has been proposed (Wang et al., 2009; Shao et al., 2009). A new nonlinear hybrid controller composed of a proportional controller, a fuzzy controller and a classical PID controller for the model attained has been introduced. A similar work to identify the model of electro-hydraulic actuator also had been done (Zulfatman and Rahmat, 2009). However, the proposed PID controller for the model obtained is applied in simulation mode only without applying it in real time mode. The electrohydraulic actuator is identified and modelled as linear periodic systems perturbed along periodic input and output trajectories (Dean and Tsao, 1998). Periodic repetitive controller is designed and implemented within the valid range of the linear approximation. Pseudo Binary Random Sequence (PRBS) signals were applied as input to the electro-hydraulic actuator in order to model the system. The Root Mean Square (RMS) errors between the outputs of actual plant and one-step predicted values belonging to models with different orders have been compared (Ziaei and Sepehri, 2000). A model-based Fault Detection, Identification and Estimation (FDIE) scheme has been developed for the condition monitoring of the EHA system (Wang and Syrmos, 2009). This scheme combines the use of a model of EHA system with the multiple-model estimation algorithm to evaluate if fault is present, its cause and its severity. A research has been done to develop a model reference adaptive PID control based on Radial Basis Function (RBF) neural network to improve the control performance of hydraulic parallel robot (Pei et al., 2007). RBF neural network is also used to identify the hydraulic servo system on-line and then regulate the PID parameters on-line which makes the system more adaptive. Robust design techniques are suggested for controlling the velocity of a hydraulic actuator (Skarpetis et al., 2007). The effectiveness of the controllers for the system is illustrated through simulations for several values of the model's uncertain parameters. On the other hand, state estimation of electro-hydraulic actuator by using proportional integral observer is presented (Perla and Mukhopadhyay, 2004). The proposed approach utilizes the complete model of the system including the nonlinear dynamics. The observer performance is demonstrated with the simulated results.

An adaptive control scheme is offered in order to overcome the large variation of the effective bulk modulus of the working fluid which is due to the absence of a heat exchanger (Le et al., 2009). This new scheme uses the error equations for velocity, acceleration and jerk which are generated in the design procedure of the standard back-stepping control scheme. Dynamic model of the entire actuator incorporating highly non-linear hydraulic functions and the LuGre dynamic friction model is used to arrive at a suitable controller (Zeng and Sepehri, 2008). An adaptive observer is used in the controller to avoid the use of acceleration measurement. A new control scheme called repetitive control is proposed in which the controlled variables follow periodic reference commands (Hara et al., 1988). Sufficient conditions for the stability of repetitive control systems and modified repetitive control systems are derived by applying the small gain theorem and the stability theorem for timelag systems. Various robust control techniques such as integral-block, sliding mode and $\mathrm{H}$-infinity control are combined to design controller forcing EHA system to track a chaotic reference trajectory (Loukianov et al., 2009). This approach enables one to compensate the inherent nonlinearities of the actuator and reject matched external disturbances and attenuate mismatched external disturbances.

Block control, sliding mode control and integral control techniques has been combined to design a controller in order to force an EHA system driven by servovalve to track a given chaotic trajectory (Avila et al., 2004). Thus, it is able to compensate the inherent nonlinearities of the actuator and to reject external constant disturbances. A sliding mode control technique is applied to design a discontinuous controller which is able to track force reference trajectory system (Lizalde et al., 2005). Siding mode controller with varying boundary layers instead of fixed boundary layers has been proposed to improve the tracking performance of a nonlinear EHA position servo system (Chen et al., 2005). A robust timeinvariant controller is designed for EHA system using a method called nonlinear Quantitative Feedback Theory (QFT) (Niksefat et al., 2000). A new control strategy which combines the classical fuzzy control theory and tri-state valve technology is presented in order to form a discontinuous controller for hydraulic valve (Zheng, 1997). An integrated hybrid design, consisting of two independent sets of cylinder controllers (a feed forward controller and a fuzzy tracking controller) and one coordinate fuzzy controller is proposed for a dualcylinder electro-hydraulic lifting system (Chen et al., 2007). The system is used to achieve a synchronized positioning objective with unbalanced loadings, uncertainties and disturbances.

Modeling of electro-hydraulic actuator system: A mathematical model of electro-hydraulic actuator consists of the dynamics of the system disturbed by an external load and the dynamics of a servo valve. The 
linearized differential equations that describe the actuator-valve dynamics are given by (Skarpetis et al., 2007):

$$
\begin{aligned}
& \dot{\mathrm{v}}_{\mathrm{p}}(\mathrm{t})=\frac{1}{\mathrm{~m}}\left[A \mathrm{P}_{\mathrm{L}}(\mathrm{t})-\mathrm{bv}_{\mathrm{p}}(\mathrm{t})-\mathrm{F}_{\mathrm{L}}(\mathrm{t})\right] \\
& \dot{\mathrm{P}}_{\mathrm{L}}(\mathrm{t})=\frac{4 \beta}{\mathrm{V}}\left[\mathrm{K}_{\mathrm{f}} \mathrm{x}_{\mathrm{v}}(\mathrm{t})-\mathrm{K}_{\mathrm{tp}} \mathrm{P}_{\mathrm{L}}(\mathrm{t})-A v_{p}(\mathrm{t})\right]
\end{aligned}
$$

Where

$\mathrm{V}_{\mathrm{p}}=$ Piston velocity

$\mathrm{P}_{\mathrm{L}}=$ Hydraulic pressure

$\mathrm{F}_{\mathrm{L}}=$ External load disturbance

$\mathrm{X}_{\mathrm{V}}=$ Spool value displacement

$\mathrm{A}=$ Piston surface area

$\mathrm{m}=$ Mass of the load

$\beta=$ Effective bulk mod ulus

$\mathrm{b}=$ Viscous damping coefficient

$\mathrm{V}=$ total volume of hydraulic oil in the piston chamber and connection lines

For zero initial conditions, the Laplace transform of the Eq. 1-2 produced the following input-output relation:

$\mathrm{U}_{\mathrm{p}}(\mathrm{s})=\mathrm{H}(\mathrm{s}) \mathrm{X}_{\mathrm{v}}(\mathrm{s})+\mathrm{H}_{\mathrm{L}}(\mathrm{s}) \mathrm{F}_{\mathrm{L}}(\mathrm{s})$

Where:

$$
\begin{aligned}
& \mathrm{H}(\mathrm{s})=\frac{4 \beta \mathrm{AK}_{\mathrm{f}}}{(\mathrm{ms}+\mathrm{b})\left(\mathrm{Vs}+4 \beta \mathrm{K}_{\mathrm{tp}}\right)=4 \mathrm{bA}^{2}} \\
& \mathrm{H}_{\mathrm{L}}(\mathrm{s})=\frac{-4 \beta \mathrm{K}_{\mathrm{tp}}-\mathrm{sV}}{(\mathrm{ms}+\mathrm{b})\left(\mathrm{Vs}+4 \beta \mathrm{K}_{\mathrm{tp}}\right)+4 \mathrm{bA}^{2}}
\end{aligned}
$$

The transfer function of solenoid can be approximated by the servo valve spool position gain denoted by $\mathrm{k}_{\mathrm{v}}$. Thus, input-output relation (3) can be rewritten as:

$\mathrm{U}_{\mathrm{p}}(\mathrm{s})=\mathrm{H}(\mathrm{s}) \mathrm{k}_{\mathrm{v}} \mathrm{V}_{\text {in }}(\mathrm{s})+\mathrm{H}_{\mathrm{L}}(\mathrm{s}) \mathrm{F}_{\mathrm{L}}(\mathrm{s})$

where, $\mathrm{V}_{\text {in }}(\mathrm{s})=$ laplace transform of the control voltage $\mathrm{v}_{\text {in }}(\mathrm{t})$.

Using Eq. 1-2, linear system with uncertain structure is derived in state space form as:

$$
\begin{aligned}
& \frac{d}{d t} x(t)=A_{0}(q) x(t) \_B_{0}(q) v_{\text {in }}(t)+D_{0} F_{L}(t) \\
& y(t)=C_{0} x(t)
\end{aligned}
$$

Where:

$$
\begin{aligned}
& \mathrm{x}(\mathrm{t})=\left[\begin{array}{l}
\mathrm{v}_{\mathrm{p}}(\mathrm{t}) \\
\mathrm{P}_{\mathrm{L}}(\mathrm{t})
\end{array}\right] \\
& \mathrm{A}_{0}(\mathrm{q})=\left[\begin{array}{ll}
-\mathrm{b} / \mathrm{m} & \mathrm{A} / \mathrm{m} \\
-4 \mathrm{q}_{1} \mathrm{~A} / \mathrm{V} & -4 \mathrm{q}_{1} \mathrm{q}_{2} / \mathrm{V}
\end{array}\right] \\
& \mathrm{B}_{0}(\mathrm{q})=\left[\begin{array}{l}
0 \\
4 \mathrm{q}_{1} \mathrm{q}_{3} \mathrm{k}_{\mathrm{v}} / \mathrm{V}
\end{array}\right] \\
& \mathrm{D}_{0}=\left[\begin{array}{ll}
-1 / \mathrm{m} \\
0
\end{array}\right] \\
& \mathrm{C}_{0}=\left[\begin{array}{ll}
1 & 0
\end{array}\right]
\end{aligned}
$$

The objectives of this study are to represent a mathematical model of Electro-Hydraulic Actuator (EHA) system using system identification technique. It is followed by designing suitable PID controller for the system in simulation and real-time mode.

Experimental and simulation setup: The electrohydraulic system that is used in this study is composed of a single-rod hydraulic cylinder driven by a direct servo valve Bosch Rexroth 4WREE6, 40 lpm flow rate at 70 bars. The dimension of hydraulic cylinder is $63 / 30 / 300 \mathrm{~mm}$. Piston position is measured by using $300 \mathrm{~mm}$ draw wire sensor. About 100 bar pressure transducers are attached to measure the pressure into and from the cylinder. NI PCI 6221 card is used as interface between MATLAB'S programs in PC with electro-hydraulic test bed.

Since the model and parameters of electrohydraulic actuator are unknown, appropriate technique which is known as System Identification is applied to attain the model of the system. The experiment starts with injected multi sine input to the EHA system through SIMULINK to capture the position of the load recorded by draw wire sensor. The collected input and output data that has been stored in workspace MATLAB then is used for model estimation and validation part. Validation process is done to compare the estimated model output with the real output from the experiments (Ljung, 1999). The validated model can be accepted based on the best fit criterion and other related specifications (Zulfatman and Rahmat, 2009). The response of the model obtained then is tested using step and sine input without any controller so that a suitable controller can be designed to improve the performance of the system.

PID controller is designed based on ZieglerNichols tuning method. The calculated parameters are inserted in PID block in SIMULINK and the output result is examined. The PID controller for the system is 
tested in two different ways. Firstly, it is operated in simulation mode which the PID controller is connected to the discrete transfer function model in SIMULINK block only. The output response is observed and recorded. Then, the similar PID is inserted in a realtime system. In this step, the PID controller with same parameters as simulation PID is located in the forward path of real-system. The different between this mode and the previous mode is the latter used the electrohydraulic actuator system itself instead of discrete transfer function model in the previous one. The output response is also recorded and compared with the output response attained from the simulation mode.

Estimation of the model: The electro-hydraulic actuator system used in this work is shown in Fig. 1.

It is an open-loop system with draw wire sensor which acts as position sensor to track the location of the load. Multi sine signal with three different frequencies is chosen as the input to the system (Taib et al., 2007). This signal is preferable compared to original sinusoidal signal in order to capture the dynamic characteristic of EHA system. The signal is represented by Eq. 9 and illustrated in Fig. 2:

multisine $=\cos \left(0.5 t_{s}\right)+\cos \left(2 t_{s}\right)+\cos \left(5 t_{s}\right)$

This signal is given to the EHA system and the output of the system is recorded. Several input output data from the experiments are collected for model estimation and validation. 1500 number of data are collected with sampling time $50 \mathrm{~m} \mathrm{sec}$.

Controller design: Proportional Integral Derivative (PID) control is one of the earlier control strategies. Its early implementation was in pneumatic devices, vacuum and solid state analogue electronics before arriving at today's digital implementation of microprocessors. It has simple control structure which was understood by plant operators and which they found relatively easy to tune. Since many control system using PID control have proved satisfactory, it still have wide range of applications in industrial control.

The performance of the system such as rise time, overshoot, settling time and steady state error can be improved by tuning the value of $\mathrm{K}_{\mathrm{p}}, \mathrm{K}_{\mathrm{i}}$ and $\mathrm{K}_{\mathrm{d}}$ of the PID controller. $K_{p}$ or proportional controller is used to assure the output reach the reference input. However, the output of the system with this controller will never reach zero steady state error. In order to obtain zero or very small steady state error, $\mathrm{K}_{\mathrm{i}}$ or integral controller is given to the system. Derivative controller or $\mathrm{K}_{\mathrm{d}}$ will improve the speed performance of the system.

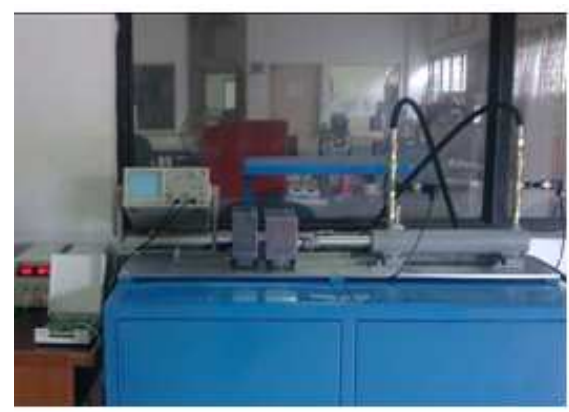

Fig. 1: Electro-hydraulic actuator system

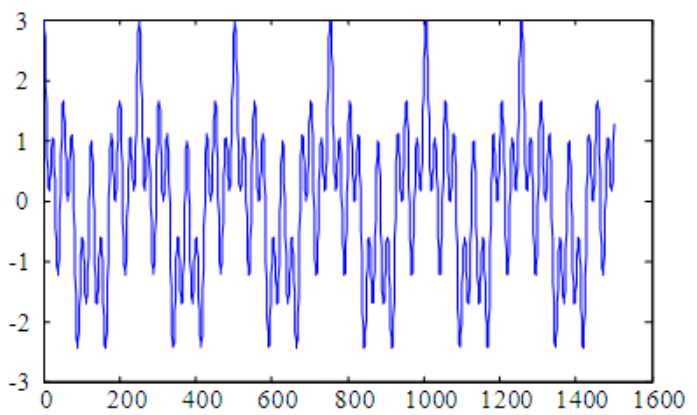

Fig. 2: Multi sine signal with three different frequencies

Table 1: The value of $K_{p}, K_{i}$ and $K_{d}$ for PID controller using ZieglerNichols tuning method Calculation of characteristic values

\begin{tabular}{llllll} 
Controller & - & - & & \\
type & $\mathrm{K}_{\mathrm{p}}$ & $\mathrm{T}_{\mathrm{i}}$ & $\mathrm{T}_{\mathrm{d}}$ & $\mathrm{K}_{\mathrm{i}}$ & $\mathrm{K}_{\mathrm{d}}$ \\
\hline $\mathrm{P}$ & $0.5 \mathrm{~K}_{\mathrm{cr}}$ & - & - & - & - \\
$\mathrm{PD}$ & $0.8 \mathrm{~K}_{\mathrm{cr}}$ & - & $0.12 \mathrm{~T}_{\mathrm{cr}}$ & - & $\mathrm{K}_{\mathrm{px}} \mathrm{T}_{\mathrm{d}}$ \\
$\mathrm{PI}$ & $0.45 \mathrm{~K}_{\mathrm{cr}}$ & $0.85 \mathrm{~T}_{\mathrm{cr}}$ & - & $\mathrm{K}_{\mathrm{p}} / \mathrm{T}_{\mathrm{i}}$ & - \\
$\mathrm{PID}$ & $0.6 \mathrm{~K}_{\mathrm{cr}}$ & $0.5 \mathrm{~T}_{\mathrm{cr}}$ & $0.12 \mathrm{~T}_{\mathrm{cr}}$ & $\mathrm{K}_{\mathrm{p}} / \mathrm{T}_{\mathrm{i}}$ & $\mathrm{K}_{\mathrm{px}} \mathrm{T}_{\mathrm{d}}$ \\
\hline
\end{tabular}

Sometimes derivative action may not be required since the proportional and integral action already produce good output response (Ogata, 2001). The tuning value of $K_{p}, K_{i}$ and $K_{d}$ are determined by using ZieglerNichols tuning method (O'Dwyer, 2003; Ogata, 2001). The tuning method begin with finding the critical gain, $\mathrm{K}_{\mathrm{cr}}$ and critical period of oscillation, $\mathrm{T}_{\mathrm{cr}}$. The value of $\mathrm{K}_{\mathrm{p}}, \mathrm{K}_{\mathrm{i}}$ and $\mathrm{K}_{\mathrm{d}}$ is adjusted from this two parameters based on Table 1 . These calculated values are only the reference value. $K_{p}, K_{i}$ and $K_{d}$ might be adjusted manually around this value to produce the best output response.

\section{RESULTS}

Estimated model: The input and related output data of the electro-hydraulic system with multi sine input injected to it is shown in Fig. 3. 

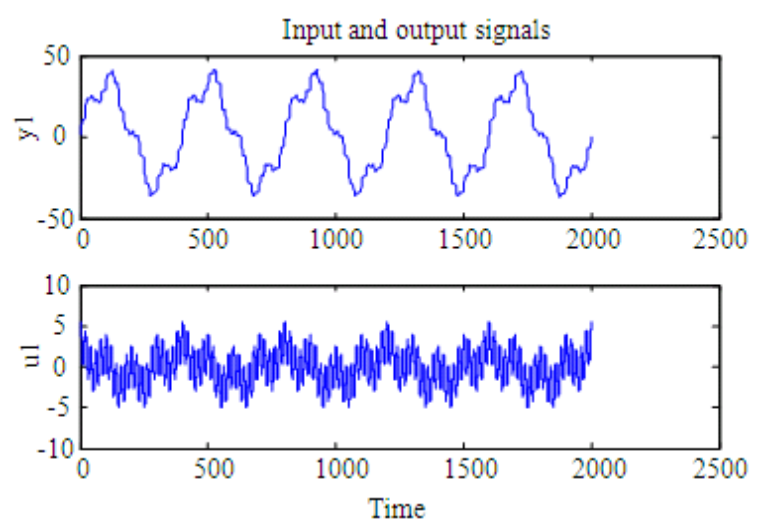

Fig. 3: The input-output data of EHA system

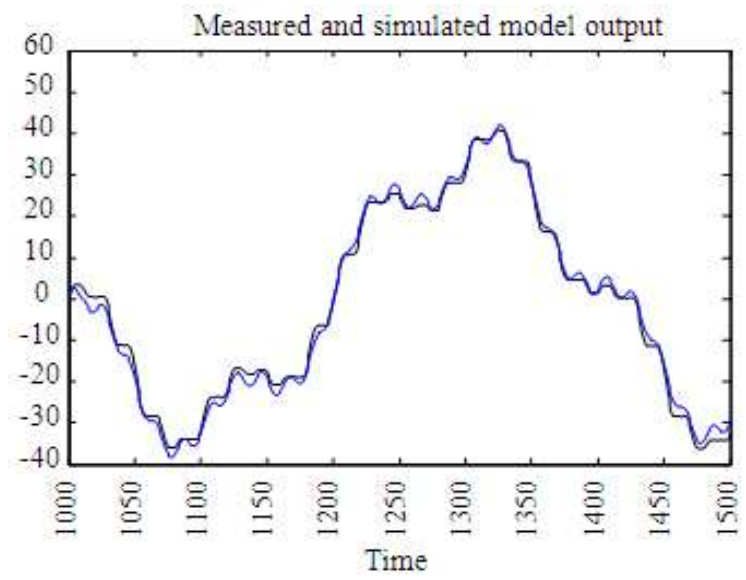

Fig. 4: The best fit graph of the estimated model

The steps to estimate the model is completed by System Identification Toolbox in MATLAB. The data obtained is divided into two parts. The first part is used to estimate the model of the system while the other part for model validation.

Auto-Regressive Exogenous (ARX) model is selected as the model structure of the system. The model can be accepted when the best fit percentage is more than 90\% (Ljung, 1999). Besides, from the residuals analysis, the auto correlation and cross correlation of input and output data should be in the range of confidence interval. Validation of the data obtained shows that $92.8 \%$ best fit meaning that the estimated model is almost tracking the real output data from the experiments. It can be seen in Fig. 4.

The residuals graph in Fig. 5 also revealed that the auto correlation and cross correlation of the input and output data are within the range of confidence interval.

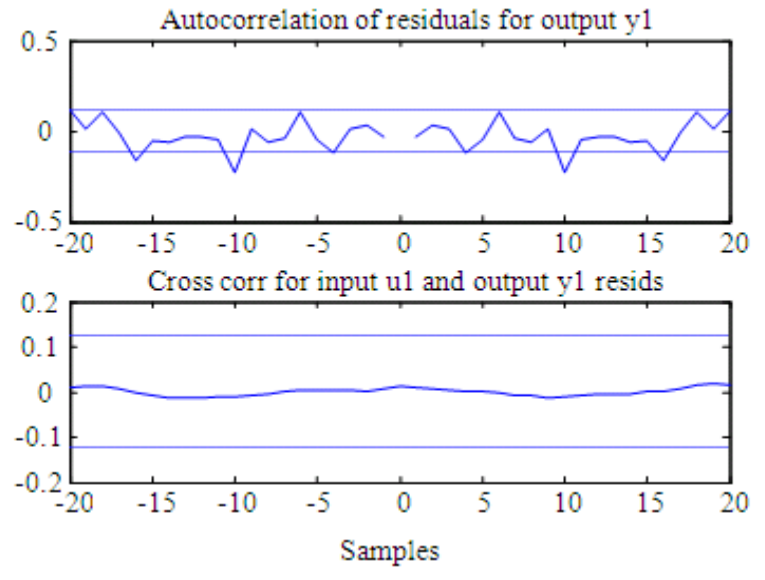

Fig. 5: The residuals graph

Table 2: The calculated value of $\mathrm{K}_{\mathrm{p}}, \mathrm{K}_{\mathrm{i}}$ and $\mathrm{K}_{\mathrm{d}}$ for PID controller

\begin{tabular}{llll}
\hline Input & $\mathrm{K}_{\mathrm{p}}$ & $\mathrm{K}_{\mathrm{i}}$ & $\mathrm{K}_{\mathrm{d}}$ \\
\hline Step & 0.276 & 0.028 & 0.09 \\
Sine & 1.800 & 0.030 & 0.01 \\
\hline
\end{tabular}

The polynomial model attained is in the form of discrete time equation which is represented as follow:

$$
\begin{aligned}
& \mathrm{A}(\mathrm{q}) \mathrm{y}(\mathrm{t})=\mathrm{B}(\mathrm{q}) \mathrm{u}(\mathrm{t})+\mathrm{e}(\mathrm{t}) \\
& \mathrm{A}(\mathrm{q})=1-2.056 \mathrm{q}^{-1}+1.186 \mathrm{q}^{-2}+0.177 \mathrm{q}^{-3} \\
& -0.3061 \mathrm{q}^{-4} \\
& \mathrm{~B}(\mathrm{q})=0.01944 \mathrm{q}^{-1}+0.6005 \mathrm{q}^{-2}-1.014 \mathrm{q}^{-3} \\
& +0.5188 \mathrm{q}^{-4}
\end{aligned}
$$

The loss function $=0.0200356$ while FPE criterion $=0.020658$.

The transfer function for ARX model is given by (Ljung, 1999) $\mathrm{G}(\mathrm{q})=\frac{\mathrm{B}(\mathrm{q})}{\mathrm{A}(\mathrm{q})}$.

Thus, the transfer function for the system can be represented by:

$$
\begin{aligned}
G(q)= & \frac{0.01944 q^{-1}+0.6005 q^{-2}-1.014 q^{-3}}{1-2.056 q^{-1}+1.186 q^{-2}+0.177 q^{-3}} \\
& -0.3061 q^{-4}
\end{aligned}
$$

PID controller: The critical gain for the model obtained is $\mathrm{K}_{\mathrm{c}}=0.46$ with critical period, $\mathrm{T}_{\mathrm{c}}=7.1481$. From calculation based on Table 1 and manual adjustment, the parameters of PID controller with different input are shown in Table 2. 


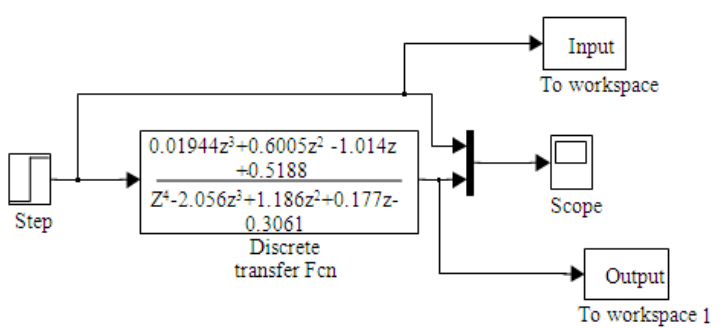

Fig. 6: The model with step input

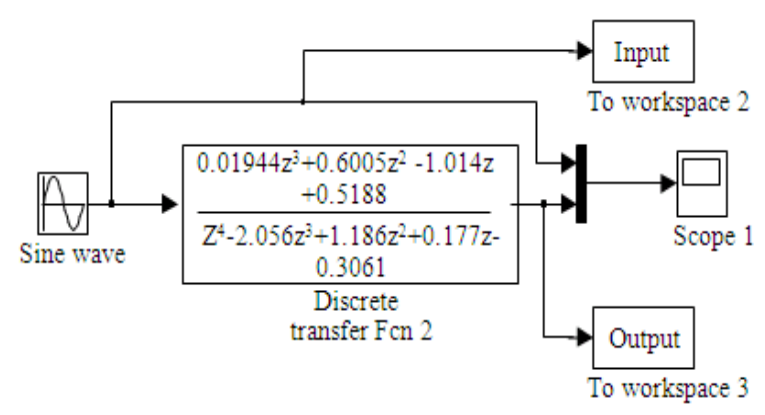

Fig. 7: The model with sine input

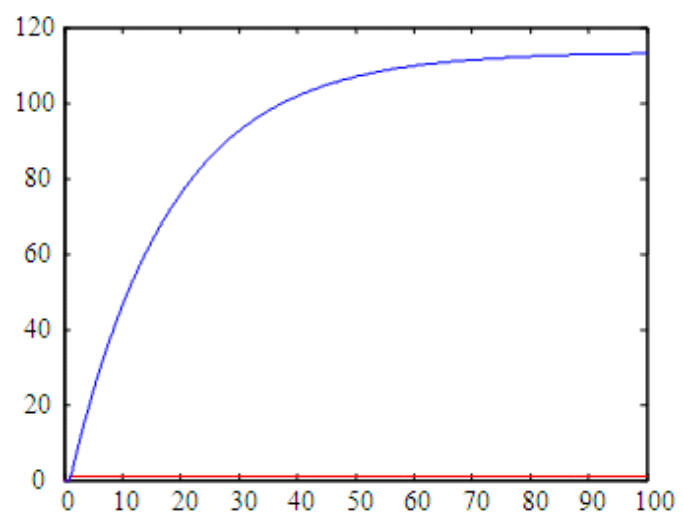

Fig. 8: Response of the model with step input

Figure 6 and 7 show the block diagram of the model without controller with step and sine input respectively. The output response with each input is illustrated in Fig. 8 and 9.

The block diagram of the system with PID controller can be seen in Fig. 10 and 11 and the output response is illustrated by Fig. 12 and 13.

These responses are obtained through simulation mode. Figure 14 shows the similar PID is inserted in the forward path of the system in real-time mode.

Based on this Figure 14, the response of the system with step and sine input are revealed by Figure 15 and 16 respectively.

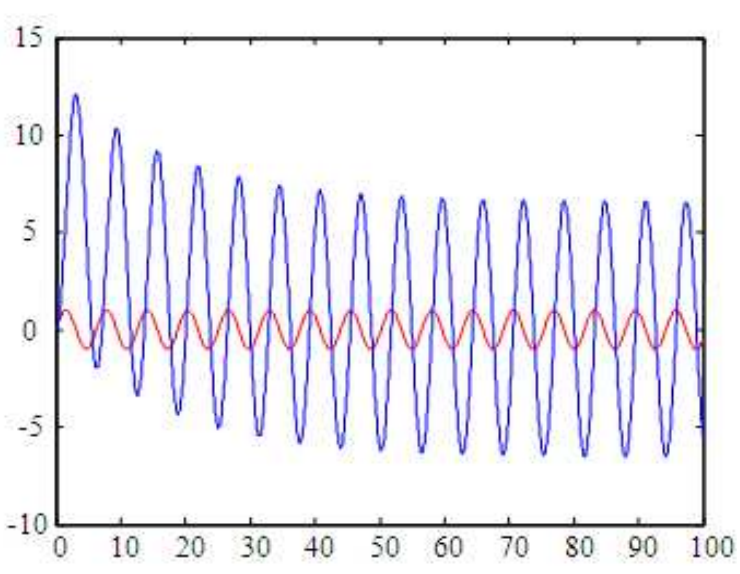

Fig. 9: Response of the model with sine input

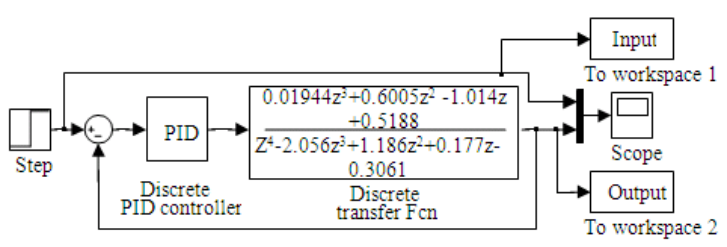

Fig. 10: System with PID controller with step input

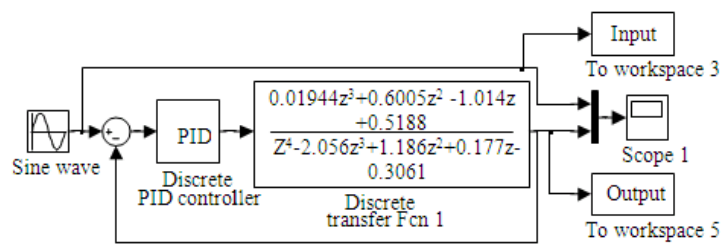

Fig. 11: System with PID controller with sine input

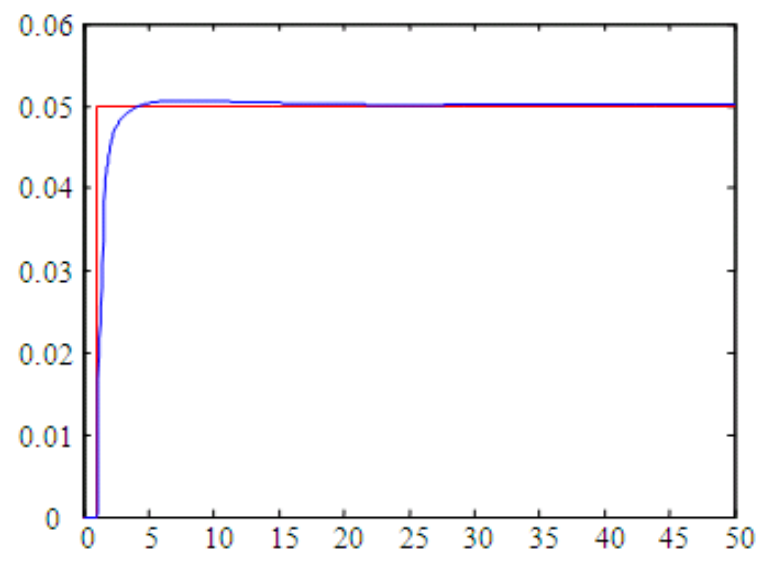

Fig. 12: Response of the system with PID controller with step input (simulation) 


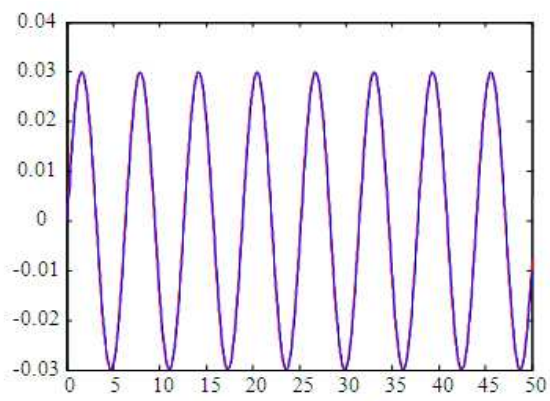

Fig. 13: Response of the system with PID controller with sine input (simulation)

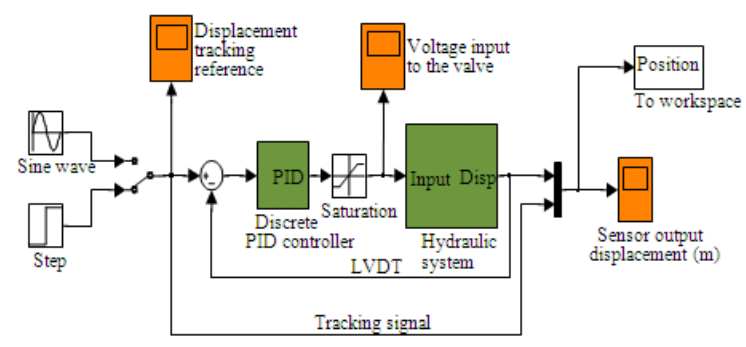

Fig. 14: Real-time PID controller

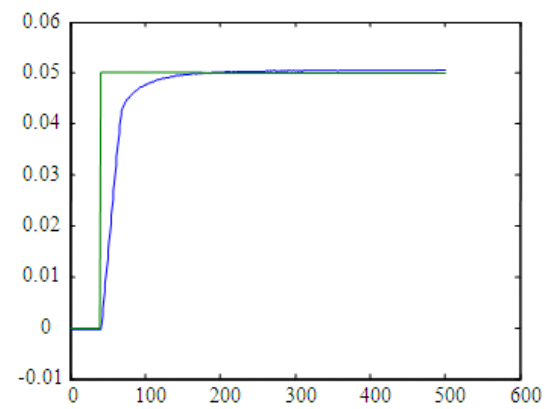

Fig. 15: Response of real-time PID controller with step input (experiment)

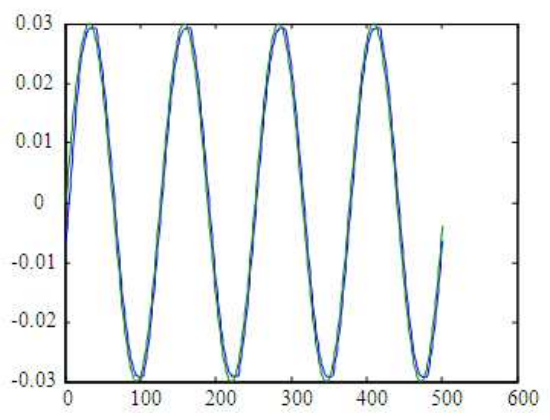

Fig. 16: Response of real-time PID controller with sine input (experiment)

\section{DISCUSSION}

Based on Eq. 11, the frequency response and the step response of the model are observed. Figure 17 and 18 demonstrate the frequency response and step response of the model respectively.

Although the model is accepted as the best model for the system by looking at short rise time, fast response and settling time of the step response, the stability of the model need to be improved. This is because based on the frequency response analysis; the phase plot does not give $180^{\circ}$ when amplitude is in zero magnitude.

The ARX model obtained by injected with step and sine input as shown in the Fig. 6 and 7 respectively. The system is simulated in open loop condition without controller. The output responses of these two Fig. 6 and 7 are shown in Figure 8 and 9 correspondingly. Referring to Fig. 8, the system produced large steady-state error when step input is injected to it.

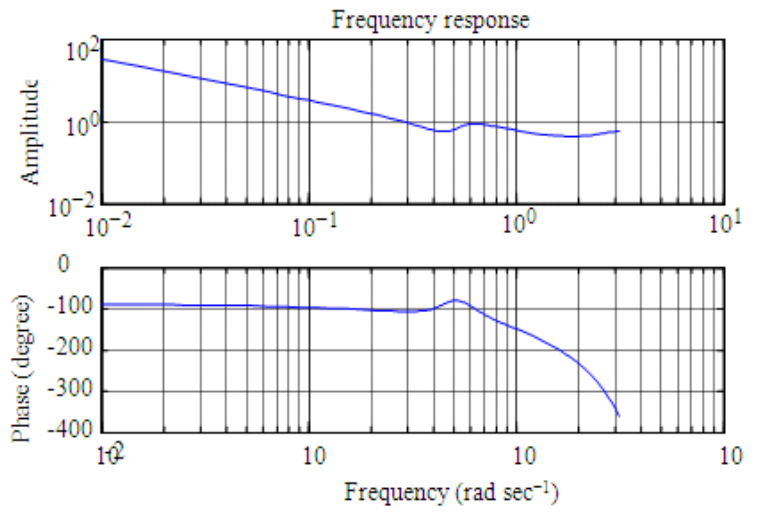

Fig. 17: Frequency response of the system

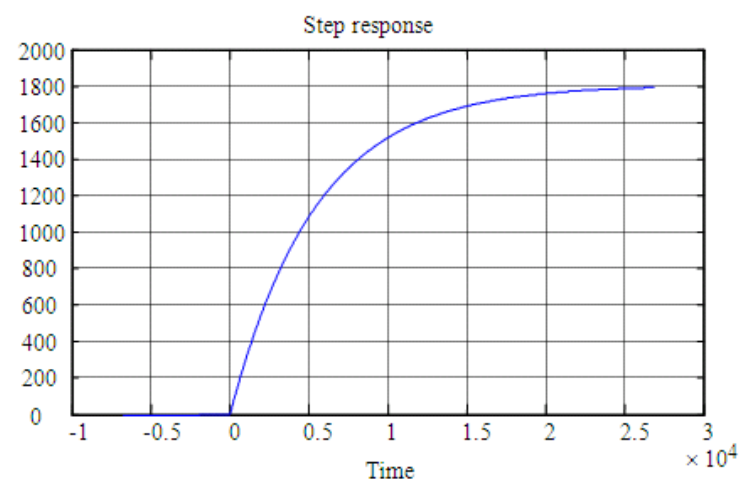

Fig. 18: Step response of the system 
Figure 9 also illustrates that the sine input caused the output of the system being unstable and oscillate. Figure 10 and 11 shows that PID controller had been applied to the forward path of the system with two different input i.e., step and sine input signal. Based on Figure 12 and 13, the output response of the system with step and sine input is improved by adding PID controller in the forward path of system. The system produced very small steady-state error with both inputs. The output of the system also tracked the input given to it. The similar PID with same parameters is inserted in forward path of real-time system in Fig. 14. Figure 15 and 16 show that the outputs from real-time experiments are almost similar with the output attained from simulation which produce very small steady-state error and fast response time. It also can be seen that the output tracked the input with very small correction. The best fit of the model also has been proved to increase from $92-98 \%$. It indicates that the setting value of $K_{p}$, $\mathrm{K}_{\mathrm{i}}$ and $\mathrm{K}_{\mathrm{d}}$ of the PID controller is acceptable and improve the performance of EHA system. A slight different between input and output happened because the electro-hydraulic system which is nonlinear model is modeled in linear model and some nonlinearity and uncertainties characteristic are ignored.

\section{CONCLUSION}

System identification technique using System Identification toolbox in MATLAB has been successfully applied to electro-hydraulic system in order to produce the best linear discrete model of the system. A suitable controller which is PID controller is designed effectively for the system and applied in simulation and real-time mode. Ziegler-Nichols method is chosen as a tuning method to determine the value of $\mathrm{K}_{\mathrm{p}}, \mathrm{K}_{\mathrm{i}}$ and $\mathrm{K}_{\mathrm{d}}$ since this tuning method is used widely. Step and sine input are injected to the system and the simulation result shows that the output tracked the input. This is also proved from the real-time experiments where the output obtained is almost similar with the output response from simulation mode.

\section{REFERENCES}

Avila, M.A., A.G. Loukianov and E.N. Sanchez, 2004. Electro-hydraulic actuator trajectory tracking. Proceeding of the 2004 American Control Conference, June 30-July 2, IEEE Xplore Press, USA., pp: 2603-2608.

Chen, H.M., J.C. Renn and J.P. Su, 2005. Sliding mode control with varying boundary layers for an electro-hydraulic position servo system. Int. J. Adv. Manuf. Technol., 26: 117-123. DOI: 10.1007/s00170-004-2145-0
Chen, C.Y. P.S. Liao and H.M. Cheng, 2007. Fuzzy controller design for positioning and synchronization of electro-hydraulic system. Proceeding of the 2nd IEEE Conference on Industrial Electronics and Application, May 23-25, IEEE Xplore Press, Harbin, pp: 971-976. DOI: 10.1109/ICIEA.2007.4318552

Dean, H.K. and T.C. Tsao, 1998. Identification and control of electro-hydraulic actuator modeled as a linear periodic system. Proceeding of The American Control Conference, June 21-26, IEEE Xplore Press, Philadelphia, PA., USA., pp: 823-827. DOI: 10.1109/ACC.1998.703523

Hara, S., Y. Yamamoto, T. Omata and M. Nakano, 1988. Repetitive control system: A new type servo system for periodic exogenous signals. IEEE Trans. Autom. Control, 33: 659-668. DOI: $10.1109 / 9.1274$

Ljung, L., 1999. System Identification: Theory for the User. 2nd Edn., Upper Saddle River Prentice-Hall, New Jersey, ISBN: 10: 0136566952, pp: 672.

Le, J.M., H.M. Kim, S.H. Park and J.S. Kim, 2009. A position control of electro-hydraulic actuator systems using the adaptive control scheme. Proceeding of the 7th Asian Control Reference, Aug. 27-29, IEEE, Hong Kong, China, pp: 21-26.

Loukianov, A.G., J. Rivera, Y.V. Orlov and E.Y.M. Teraoka, 2009. Robust trajectory tracking for an electro-hydraulic actuator. IEEE Trans. Ind. Elect., 56: 3523-3531. DOI: 10.1109/TIE.2009.2029014

Lizalde, C., A. Loukianov and E. Sanchez, 2005. Force tracking neural control for an electro-hydraulic actuator via second order sliding mode. Proceeding of the IEEE, International Symposium on Intelligent Control, June 27-29, IEEE Xplore Press, Limassol, pp: 292-297. DOI: 10.1109/.2005.1467030

Niksefat, N., Q. Wu and N. Sepehri, 2000. Stable control of an electro-hydraulic actuator during contact tasks: Theory and experiments. Proceeding of The American Control Conference, June 28-30, IEEE Xplore Press, Chicagi, IL., USA., pp: 4114-4118. DOI: 10.1109/ACC.2000.876995

O'Dwyer, A., 2003. Handbook of PI and PID Controller Tuning Rules. 2nd Edn., World Scientific, Ireland, ISBN: 186094342X, pp: 375.

Ogata, K., 2001. Modern Control Engineering. 4th Edn., Prentice-Hall, Upper Saddle River, New Jersey, ISBN: 10: 0130609072, pp: 970. 
Perla, R. and S. Mukhopadhyay, 2004. State estimation in electro-hydraulic actuator using proportional integral observer. Proceeding of the India Annual Conference, Dec. 20-22, IEEE Xplore Press, USA., pp: 233-236. DOI: 10.1109/INDICO.2004.1497746

Pei, Z., Y. Zhang and Z. Tang, 2007. Model reference adaptive PID control of hydraulic parallel robot based on RBF neural network. Proceeding of the IEEE International Conference on Robotics and Biomimetics, Dec. 15-18, IEEE Xplore Press, Sanya, pp: 1383-1387. DOI: 10.1109/ROBIO.2007.4522366

Skarpetis, M.G. F.N. Koumboulis and M.P. Tzamtzi, 2007. Robust control techniques for hydraulic actuators. Proceeding of the Mediterranean Conference on Control and Automation, June 2729, IEEE Xplore Press, Athens, pp: 1-6. DOI: 10.1109/MED.2007.4433688

Shao, J., Z. Wang, J. Lin and G. Han, 2009. Model identification and control of electro-hydraulic position servo system. Proceeding of the International Conference on Intelligent HumanMachine Systems and Cybernetics, Aug. 26-27, IEEE Xplore Press, Hangzhou, Zhejiang, pp: 210-213. DOI: 10.1109/IHMSC.2009.60

Taib, M.N., R. Adnan and M.H.F. Rahiman, 2007. Practical System Identification. 1st Edn., University of Technology Mara, Shah Alam, Malaysia, pp: 32.

Wang, Z., J. Shao, J. Lin and G. Han, 2009. Research on controller design and simulation of electrohydraulic servo system. Proceeding of the International Conference on Mechatronic and Automation, Aug. 9-12, IEEE Xplore Press, Changchun, pp: 380-338. DOI: 10.1109/ICMA.2009.5245095
Wang, X. and V.L. Syrmos, 2009. Fault detection, identification and estimation in the EHA system using multiple model estimation. Proceeding of the Aerospace Conference, Mar. 7-14, IEEE Xplore Press, Big Sky, MT., pp: 1-10. DOI: 10.1109/AERO.2009.4839662

Zulfatman, R.A. and M.F. Rahmat, 2009. Modeling and controller design of electro-hydraulic actuator. Proceeding of the 2nd International Conference on Control, Instrumentation and Mechatronic Engineering, June 9-9, UTM Publisher, Malacca, Melaka, Malaysia, pp: 225-231.

Ziaei, K. and N. Sepehri, 2000. Modeling and identification of electrohydraulic servos. Mechatronics, 10: 761-772. DOI: 10.1016/S09574158(99)00042-2

Zeng, H. and N. Sepehri, 2008. Tracking control of hydraulic actuators using a LUGRE friction model compensation. J. Dyn. Syst. Measur. Control, 130: 1-7. DOI: $10.1115 / 1.2807181$

Zheng, Y., 1997. A new control strategy for hydraulic valve applications in oil field. Proceeding of the Canadian Conference on Electrical and Computer Engineering, May 25-28, IEEE Xplore Press, St. Johns, Nfld., Canada, pp: 708-711. DOI: 10.1109/CCECE.1997.608336 